\title{
Regulation of the antioncogenic Chk2 kinase by the oncogenic Wip1 phosphatase
}

\author{
H Fujimoto ${ }^{1,7}, N_{\text {Onishi }}{ }^{1,7}$, N Kato $^{1,7}$, M Takekawa $^{2,3}, X X^{1}{ }^{1}$, \\ A Kosugi ${ }^{4}$, T Kondo ${ }^{5}$, M Imamura $^{6}$, I Oishi ${ }^{1}$, A Yoda $^{1}$ and \\ Y Minami ${ }^{\star, 1}$ \\ 1 Department of Genome Sciences, Faculty of Medical Sciences, Graduate \\ School of Medicine, Kobe University, 7-5-1, Kusunoki-cho, Chuo-ku, Kobe \\ 650-0017, Japan \\ 2 Division of Molecular Cell Signaling, Institute of Medical Science, The \\ University of Tokyo, 4-6-1, Shirokanedai, Minato-ku, Tokyo 108-8639, Japan \\ 3 PRESTO, Japan Science and Technology Corporation (JST), Kawaguchi, \\ Saitama 332-0012, Japan \\ 4 School of Allied Health Science, Faculty of Medicine, Osaka University, 1-7, \\ Yamada-oka, Suita 565-0871, Japan \\ ${ }^{5}$ Departments of Gastroenterology and Hematology, Hokkaido University, \\ Graduate School of Medicine, Kita 15 Nishi 7, Kita-ku, Sapporo, Hokkaido 060- \\ 8638, Japan \\ ${ }^{6}$ Departments of Hematology and Oncology, Hokkaido University, Graduate \\ School of Medicine, Kita 15 Nishi 7, Kita-ku, Sapporo, Hokkaido 060-8638, \\ Japan \\ 7 These authors contributed equally to this work \\ * Corresponding author: Y Minami, Department of Genome Sciences, Faculty of \\ Medical Sciences, Graduate School of Medicine, Kobe University, 7-5-1, \\ Kusunoki-cho, Chuo-ku, Kobe 650-0017, Japan. Tel: + 81-78-382-5560; \\ Fax: + 81-78-382-5579; E-mail: minami@kobe-u.ac.jp
}

Received 01.8.05; revised 26.9.05; accepted 27.9.05; published online 25.11.05 Edited by $\mathrm{H}$ Ichijo

\begin{abstract}
The antioncogenic Chk2 kinase plays a crucial role in DNA damage-induced cell-cycle checkpoint regulation. Here we show that Chk2 associates with the oncogenic protein Wip1 (wild-type p53-inducible phosphatase 1) (PPM1D), a p53inducible protein phosphatase. Phosphorylation of Chk2 at threonine68 (Thr68), a critical event for Chk2 activation, which is normally induced by DNA damage or overexpression of Chk2, is inhibited by expression of wild-type (WT), but not a phosphatase-deficient mutant (D314A) of Wip1 in cultured cells. Furthermore, an in vitro phosphatase assay revealed that Wip1 (WT), but not Wip1 (D314A), dephosphorylates Thr68 on phosphorylated Chk2 in vitro, resulting in the inhibition of Chk2 kinase activity toward glutathione $S$-transferase-Cdc25C. Moreover, inhibition of Wip1 expression by RNA interference results in abnormally sustained Thr68 phosphorylation of Chk2 and increased susceptibility of cells in response to DNA damage, indicating that Wip1 acts as a negative regulator of Chk2 in response to DNA damage.
\end{abstract}

Cell Death and Differentiation (2006) 13, 1170-1180. doi:10.1038/sj.cdd.4401801; published online 25 November 2005

Keywords: cell-cycle checkpoint; DNA damage; Chk2 kinase; Wip1 phosphatase; phosphorylation
Abbreviations: ATM, ataxia-telangiectasia mutated; FCS, foetal calf serum; PMSF, phenylmethyl sulphonyl fluoride; PP2C, type 2C protein phosphatases; Wip1, wild-type p53-inducible phosphatase 1

\section{Introduction}

The Chk2 tumour suppressor protein is an evolutionarily conserved nuclear protein kinase that plays a crucial role in the response to DNA damage and helps to maintain genomic stability by regulating cell cycle checkpoints, DNA repair, and apoptosis. $^{1-8}$ Upon DNA damage, Chk2 is activated by phosphorylation of threonine68 (Thr68) by ATM (ataxiatelangiectasia mutated). ${ }^{9-13}$ Activated Chk2 then phosphorylates its downstream effectors, including the tumour suppressors p53, BRCA1, PML, E2F-1, and Cdc25 phosphatases, ${ }^{14-19}$ thereby regulating cellular responses following DNA damage. Although the molecular basis of Chk2 kinase activation and roles of Chk2 in checkpoint activation are rather well understood, it remains largely unknown as to how activated Chk2 is inhibited to release from checkpoint arrest or to prevent cells from undergoing Chk2-mediated apoptosis.

In yeast cells, it has been recently reported that protein phosphatases play essential roles in inactivating cell-cycle checkpoint arrest induced by DNA damage. In Schizosaccharomyces pombe, the type I protein phosphatase Dis2 abrogates Chk1 phosphorylation and activation by dephosphorylating the phosphorylated-Ser345 in Chk1, thereby allowing mitotic entry following repair of damaged DNA. ${ }^{20}$ On the other hand, in Saccharomyces cerevisiae, the type 2C protein phosphatases (PP2C), Ptc2 and Ptc3, bind to Rad53, the $S$. cerevisiae orthologue of Chk2, and inactivate Rad53 presumably by dephosphorylating Rad53, leading to checkpoint inactivation upon a DNA double-strand break. ${ }^{21}$ Thus, it can be assumed that protein phosphatases may mediate the termination of DNA damage-induced cell-cycle checkpoint arrest to restart cell cycle by dephosphorylating and inactivating checkpoint kinases. Despite the high degree of conservation between cell-cycle checkpoint in yeast and mammals, it remains unknown whether or not protein phosphatases are involved in the termination of DNA damage-induced cell-cycle checkpoint arrest in mammals.

In mammals, the PP2C family of protein phosphatases consists of at least seven distinct isoforms, and have been implicated in stress response signalling. ${ }^{22-24}$ Among members of the PP2C family, in particular, Wip1 (wild-type p53-inducible phosphatase 1) (PPM1D) possesses unique biological characteristics. Wip1 is induced by DNA damage in a p53-dependent manner, and inhibits ultraviolet (UV)irradiation-induced p38 activation by dephosphorylating Thr180 in p38, thereby inhibiting the function of p53. ${ }^{24,25}$ It has been reported that the Wip1 (PPM1D) gene is amplified or overexpressed in various human cancers, including breast 
cancers, ${ }^{26-29}$ and that overexpression of Wip1 (PPM1D) complements the oncogenes Ras, Myc, and Neu1 for transformation of wild-type mouse embryonic fibroblasts (MEFs). ${ }^{26}$ More recently, it has been shown that Wip1 associates with the nuclear isoform of uracil DNA glycosylase, UNG2, and that Wip1 suppresses DNA damage-induced base excision repair (BER) activity by dephosphorylating and inactivating UNG2. ${ }^{30}$

In this study, we show that Wip1 interacts with Chk2 both physically and functionally in the nuclei. Wip1 dephosphorylates Thr68 in activated Chk2 both in vitro and in vitro, and inactivates Chk2 kinase activity toward Cdc25C. Furthermore, inhibition of Wip1 expression by RNA interference (RNAi) with Wip1 siRNA or p53 siRNA results in abnormally sustained Thr68 phosphorylation and kinase activation of Chk2 in response to DNA damage. We further show that RNAi-mediated inhibition of Wip1 expression results in enhanced apoptosis following DNA damage, and that ectopic expression of Wip1 suppresses Chk2-mediated apoptosis. Collectively, our in vitro and in vivo evidence suggests that Wip1 acts as a negative regulator of Chk2 during DNA damage responses, and that Wip1 plays an essential role in terminating DNA damage-induced cell-cycle checkpoint activation or in preventing cells from undergoing Chk2mediated apoptosis in response to DNA damage.

\section{Results and Discussion}

\section{Association of Chk2 with Wip1 in the nuclei}

To better understand the roles and regulation of Chk2 during the DNA damage responses, we performed yeast two-hybrid screening using human Chk2 as a bait to identify potential associating molecule(s). From this screen, we identified Wip1, a p53-inducible oncogenic nuclear protein serine (S)/threonine $(T)$ phosphatase ${ }^{24-28}$ (data not shown). To test whether Chk2 can associate with Wip1 in vitro, we performed pulldown analyses using glutathione S-transferase (GST)-Chk2 (wild-type (WT)) or GST-Wip1 (WT) purified from Escherichia coli. As shown in Figure 1a, Flag-tagged Wip1 (WT) expressed in 293T cells associated specifically with GSTChk2 (WT), but not with GST. Conversely, haemagglutinin (HA)-tagged Chk2 (WT) expressed in 293T cells associated specifically with GST-Wip1 (WT), but not with GST (Figure 1b). These results indicate that Chk2 associates with Wip1 in vitro. Since it has been reported previously that both Chk2 and Wip1 are localized in the nuclei, $7,17,25,31$ their intracellular distribution was examined by immunofluorescence in 293T cells coexpressing HA-tagged GST-Chk2 (GST-HA-Chk2) and Flag-tagged Wip1 (Flag-Wip1) (see Materials and Methods). GST-HA-Chk2 and Flag-Wip1 colocalized primarily in the nuclei (see Supplementary Information). To determine whether Chk2 can associate with Wip1 in vivo, Flag-Wip1 (WT) was transiently expressed in 293T cells, either alone or with GST-HA-Chk2 (WT). Cells were harvested, and protein association was evaluated by co-precipitation with glutathione-Sepharose, followed by anti-Flag-immunoblotting. As shown in Figure 1c, in cells expressing both GST-HA-Chk2 and Flag-Wip1, glutathione-
Sepharose precipitation specifically co-precipitated Wip1, indicating that Chk2 associates with Wip1 in 293T cells.

We next examined whether endogenous Chk2 and Wip1 can interact in intact cells. To this end, we generated polyclonal anti-Chk2 and anti-Wip1 antibodies raised against human Chk2 peptides (amino acids (a.a.) 523-543) and GSThuman Wip1 (a.a. 1-458), respectively (see Materials and Methods), and evaluated specificities for their antigen recognition. As shown in Figure 1d (left panel), immunoblotting with anti-Chk2 antibody clearly detected HA-Chk2 (upper band) and endogenous Chk2 (lower band) in wholecell lysates and HA-Chk2 in anti-HA immunoprecipitates from 293T cells expressing HA-Chk2, and preadsorption of antiChk2 antibody with GST-Chk2 prior to immunoblotting resulted in a failure of the detection of HA-Chk2, confirming the specificity of anti-Chk2 antibody. Similarly, immunoblotting with anti-Wip1 antibody specifically detected FlagWip1 (Figure 1d, right panel). Specificities of anti-Wip1 and anti-Chk2 antibodies were further confirmed by an RNAi experiment where the bands detected by anti-Wip1 and antiChk2 antibodies were diminished in cells treated with Wip1 siRNAs and Chk2 siRNAs, respectively (Figure 4, data not shown). We examined the association of endogenous Chk2 and Wip1 in MCF7 cells that express Wip1 at a higher level. As shown in Figure 1e, endogenous Chk2 and Wip1 associated in MCF7 cells.

\section{Effect of Wip1 on Thr68 phosphorylation of Chk2 induced by DNA damage or overexpression of Chk2}

It was shown that ectopic overexpression of Chk2 in 293T cells results in its electrophoretic mobility shift (Figure 2a), ${ }^{13,32}$ indicating auto- or transphosphorylation. In fact, electrophoretic mobility shift induced by overexpression of Chk2 was abrogated following treatment of cell extracts with CIP or BAP (data not shown). To examine the functional significance of the association between Wip1 and Chk2, HA-Chk2 (WT) or HA-Chk2 (DK) was expressed in 293T cells along with either Flag-Wip1 (WT) or Flag-Wip1 (D314A). Chk2 electrophoretic mobilities were monitored by anti-HA-immunoblotting of whole-cell lysates. Overexpression of Chk2 (WT), but not Chk2 (DK), resulted in decreased electrophoretic mobility (Figure 2a), indicating that Chk2 kinase activity is required for this electrophoretic mobility shift. It had been shown previously that phosphorylation of Chk2 on Thr68 is required for full activation of Chk2 via auto- (trans- or cis)phosphorylation. ${ }^{9-13,31-34}$ We therefore investigated the role of Thr68phosphorylation in the electrophoretic mobility shift of Chk2. We found that a Chk2 mutant, the alanine68 mutant (HA-Chk2 $(T 68 A)$ ), did not undergo the mobility shift when overexpressed (data not shown), indicating that Thr68 is required. Intriguingly, this mobility shift was abrogated by coexpression of Wip1 (WT), but not Wip1 (D314A) (Figure 2a), suggesting that Wip1 phosphatase activity can counteract Chk2 phosphorylation either directly or indirectly.

It has been shown previously that $\gamma$-irradiation induces Thr68-phosphorylation and modification (activation) of Chk2. ${ }^{9-13}$ Hence, we examined Thr68-phosphorylation and 

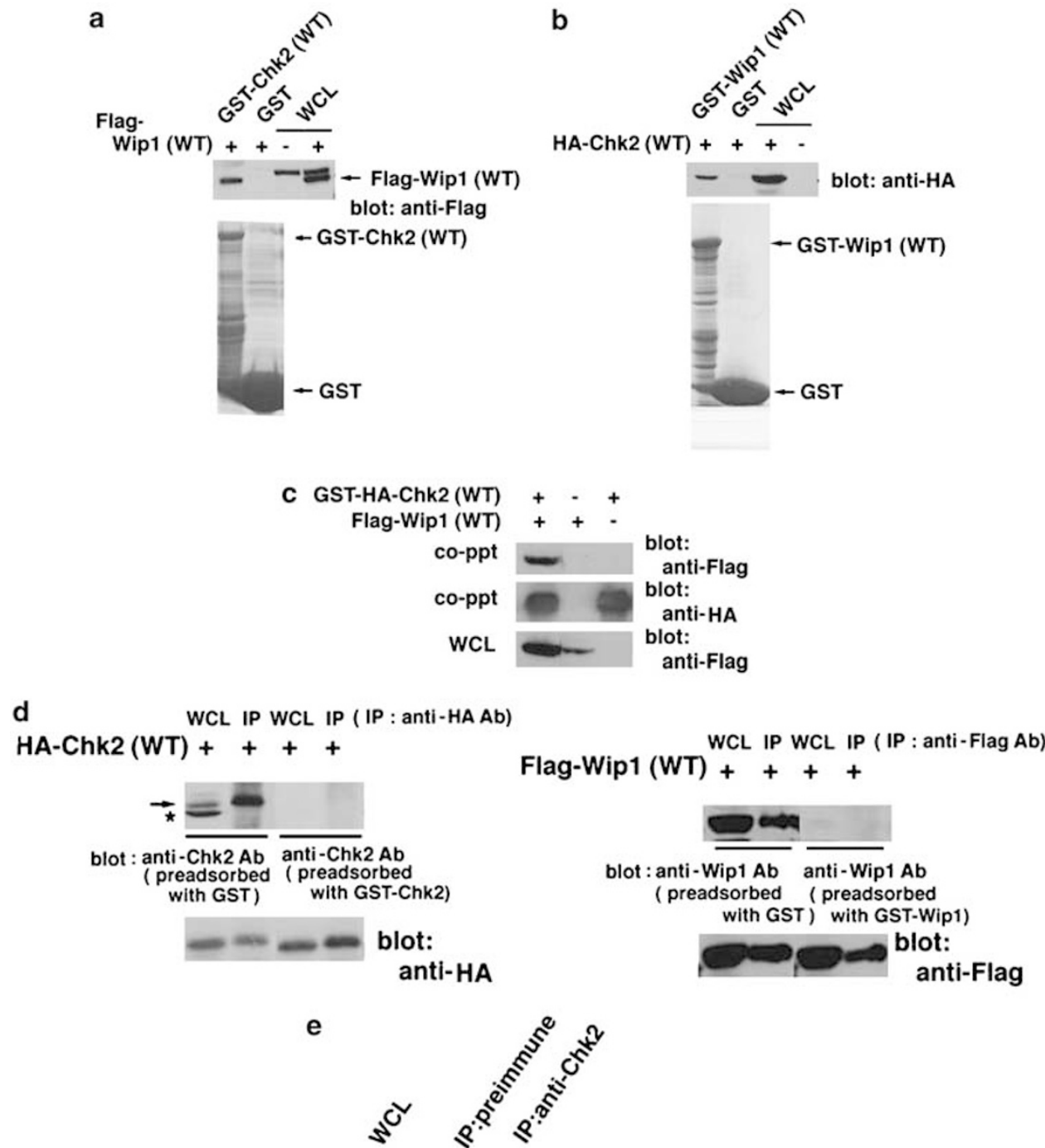

\section{blot: anti-Wip1 \\ blot: anti-Chk2}

Figure 1 Association of Chk2 kinase with Wip1 phosphatase both in vitro and in vivo. (a) Whole-cell lysates (WCLs) from 293T cells expressing Flag-Wip1 were subjected to a pull-down assay (see Materials and Methods). Amounts of Flag-Wip1 bound to GST-Chk2- or GST-conjugated glutathione-Sepharose were determined by anti-Flag-immunoblotting. Upper panel, anti-Flag-immunoblotting of pull-down samples or WCLs; lower panel, CBBR staining shows amounts of the respective fusion proteins applied to the pull-down assay. (b) WCLs from 293T cells expressing HA-Chk2 were subjected to pull-down assay. Amounts of HA-Chk2 bound to GST-Wip1- o GST-conjugated glutathione-Sepharose were determined by anti-HA-immunoblotting. Upper panel, anti-HA-immunoblotting of pull-down samples or WCLs; lower panel, CBBR staining shows amounts of the respective fusion proteins applied to the pull-down assay. (c) WCLs from 293T cells, expressing Flag-Wip1 (WT) in the presence or absence of GST-HA-Chk2 (WT), were subjected to affinity precipitation with glutathione-Sepharose, followed by anti-Flag- and anti-HA-immunoblotting, respectively. Upper and middle panels, anti-Flag- and anti-HA-immunoblotting of glutathione-Sepharose-precipitated proteins, respectively; lower panel, anti-Flag-immunoblotting of WCLs. The results shown are representative of three independent experiments. (d) HA-Chk2 (left) and Flag-Wip1 (right) were expressed transiently in 293T cells. AntiHA or anti-Flag immunoprecipitates or WCLs from the respective transfectants were immunoblotted with anti-Chk2 (left) or anti-Wip1 (right) antibodies, respectively. The specificity of the respective antibodies was assessed by preadsorption with corresponding GST fusion proteins as indicated. Expressions of HA-Chk2 and Flag-Wip1 were verified by anti-HA- and anti-Flag-immunoblotting, respectively. The arrow and asterisk indicate the positions of HA-Chk2 and endogenous Chk2, respectively. (e) WCLs or immunoprecipitates with anti-Chk2 or control (preimmune) antibodies prepared from MCF7 cells were subjected to anti-Wip1 (upper) or anti-Chk2 (lower) immunoblotting

mobility shift of HA-Chk2 (WT) coexpressed with Flag-Wip1 (WT) or Flag-Wip1 (D314A) in 293T cells, before or after $\gamma$ irradiation, by immunoblotting with antiphospho-Chk2 (Thr68). As shown in Figure $2 b$ (upper panel), ectopic overexpression of HA-Chk2 per se induced some Thr68- autophosphorylation, but this phosphorylation, and that of the endogenous Chk2, was enhanced following $\gamma$-irradiation, in cells not coexpressing Flag-Wip1 (WT). Antiphospho-Chk2 (Thr68) antibody failed to detect HA-Chk2 (T68A) expressed in 293T cells, demonstrating that this antibody specifically 
recognizes phosphorylated-Thr68 in Chk2 (data not shown). However, Thr68-phosphorylation and electrophoretic mobility shift of HA-Chk2 (WT) were inhibited in cells coexpressing Wip1 (WT), but not Wip1 (D314A) (Figure 2b), indicating that the phosphatase activity of Wip1 is required for the inhibition of Chk2 Thr68-phosphorylation and mobility shift induced by overexpression of Chk2 and/or $\gamma$-irradiation, although it was unclear whether Wip1 acted directly on Chk2. Since Wip1 belongs to the PP2C family of protein phosphatases, we examined whether or not other members of the PP2C family can exhibit similar effects. Coexpression of human PP2C $\alpha 2$, mouse $\mathrm{PP} 2 \mathrm{C} \beta$, $\mathrm{PP} 2 \mathrm{C} \varepsilon$, or $\mathrm{PP} 2 \mathrm{C} \zeta$ fails to inhibit Thr68-

a

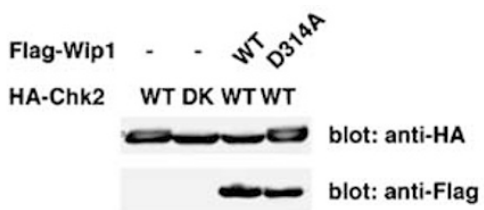

b

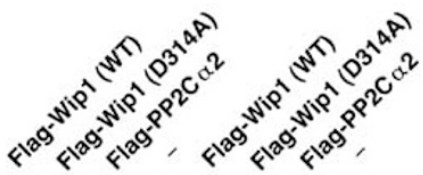

HA-Chk2 WT WT WT WT WT WT WT WT

10Gy

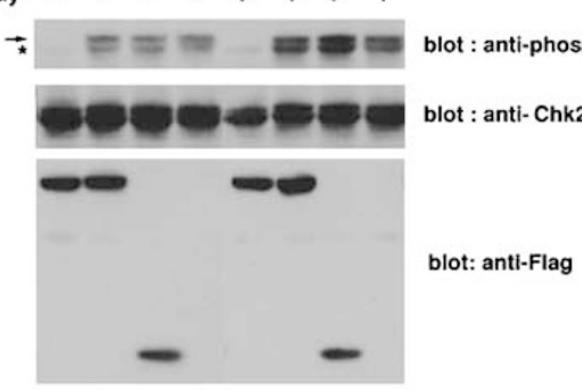

C

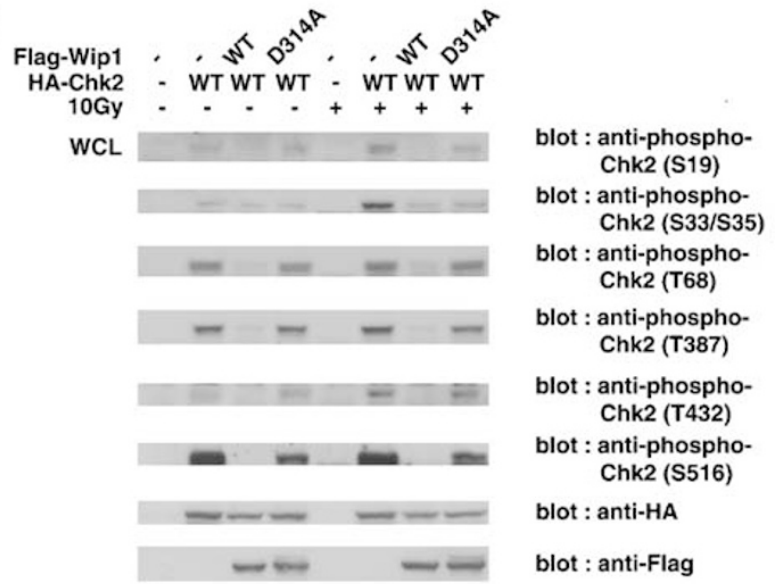

d phosphorylation and electrophoretic mobility shift of HAChk2 (WT) (Figure 2b, data not shown), indicating that the observed effects are at least selective to Wip1 among members of the PP2C family.

\section{Effect of Wip1 on other phosphorylation sites in Chk2 induced by DNA damage or overexpression of Chk2}

We next examined the effect of Wip1 (WT) on phosphorylation of several S and T residues other than Thr68 of Chk2, induced upon ectopic overexpression of Chk2 and/or $\gamma$-irradiation, by immunoblotting with a series of phospho-Chk2 antibodies. As shown in Figure 2c, ectopic overexpression of HA-Chk2 per se induced weak phosphorylation of Ser19, Ser33/35, and Thr432 and strong (or apparent) phosphorylation of Thr387 and Ser516 of Chk2, and these phosphorylations were further enhanced following $\gamma$-irradiation. Phosphorylation of Ser19, Ser33/35, Thr387, and Thr432 of HA-Chk2 induced by its overexpression and/or $\gamma$-irradiation was also inhibited in cells coexpressing Wip1 (WT), but not Wip1 (D314A) (Figure 2c). The result presented in Figure $2 \mathrm{~b}$ suggests that dephosphorylation of phosphorylated-Thr68 in Chk2 by Wip1 may inhibit subsequent phosphorylation of Chk2 at several S/T residues, or that Wip1 may dephosphorylate these phosphorylated residues in Chk2 (see Figure 3a). We also examined the effect of Wip1 (WT) on endogenous Chk2, and found that expression of Wip1 (WT), but not Wip1 (D314A), in 293T cells also inhibited Thr68-phosphorylation and mobility shift of the endogenous Chk2 (Figure 2d).

\section{Dephosphorylation of Ser19, Ser33/35, Thr68, and Thr432, but not Thr387 and Ser516 in Chk2 by Wip1 in vitro}

We next addressed the question of whether or not Wip1 could dephosphorylate Thr68 or Thr387 in Chk2. To this end, GSTWip1 (WT) and GST-Wip1 (D314A) were expressed in E. coli

Figure 2 Inhibition of Chk2 Thr68-phosphorylation and electrophoretic mobility shift by Wip1 (WT), but not Wip1 (D314A), before and after $\gamma$-irradiation. (a) Wildtype (WT) or dead-kinase mutant (DK) of HA-Chk2 proteins were expressed transiently in 293T cells along with either WT or a phosphatase-deficient mutant (D314A) of Flag-Wip1 proteins. WCLs from the respective transfectants were subjected to anti-HA- (upper) or anti-Flag- (lower) immunoblotting, respectively. (b) HA-Chk2 (WT) proteins were expressed transiently in 293T cells along with either Flag-Wip1 (WT), Flag-Wip1 (D314A), or Flag-PP2C $\alpha 2$. Before or after $\gamma$ irradiation (10 Gy), WCLs were subjected to antiphospho-Chk2 (Thr68)immunoblotting. The arrow and asterisk indicate the positions of HA-Chk2 and of endogenous Chk2, respectively. Upper, middle, and lower panels, antiphospho-Chk2 (Thr68)-, anti-HA-, and anti-Flag-immunoblotting of WCLs, respectively. Flag-PP2C $\alpha 2$ expressed in 293T cells is catalytically active, since it can dephosphorylate phosphorylated-p38 (data not shown). (c) HA-Chk2 (WT) proteins were expressed transiently in 293T cells along with either Flag-Wip1 (WT) or Flag-Wip1 (D314A) proteins. Before or after $\gamma$-irradiation (10 Gy), WCLs were subjected to antiphospho-Chk2 (Ser19, Ser33/35, Thr68, Thr387, Thr432, or Ser516)- or anti-HA-immunoblotting as indicated. WCLs were also subjected to anti-Flag-immunoblotting. (d) Flag-Wip1 (WT) or Flag-Wip1 (D314A) was expressed transiently in 293T cells. Before or after $\gamma$-irradiation (10 Gy), WCLs from the respective transfectants were subjected to antiphospho-Chk2 (Thr68)immunoblotting. Upper, middle, and lower panels, antiphospho-Chk2 (Thr68)-, anti-Chk2-, and anti-Flag-immunoblotting of WCLs, respectively 
a

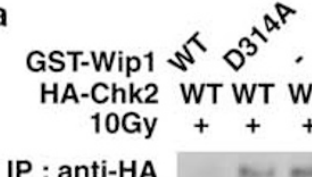

IP : anti-HA

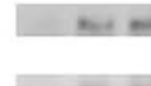

blot : anti-phosphoChk2 (S19)

blot : anti-phosphoChk2 (S33/S35)
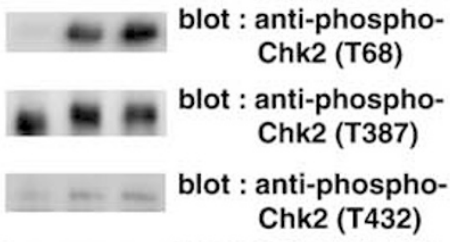

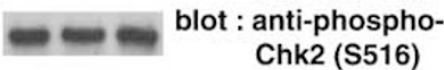

$\mathrm{E}=\mathrm{E}$ blot : anti-HA

b

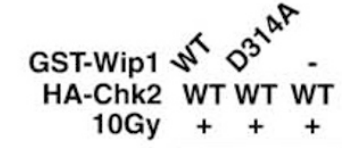

Kinase activity

CBBR

IP : anti-HA

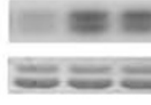

$Z^{32}$ P-GST-Cdc25C

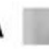

\section{$=$ GST-Cdc25C}

Chk2 (T68)

$-\infty-$ blot : anti-HA

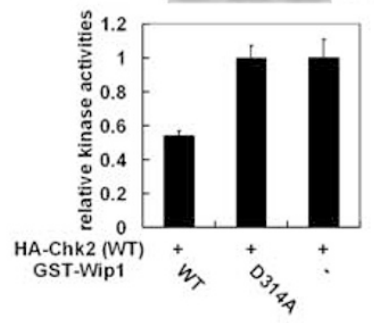

C
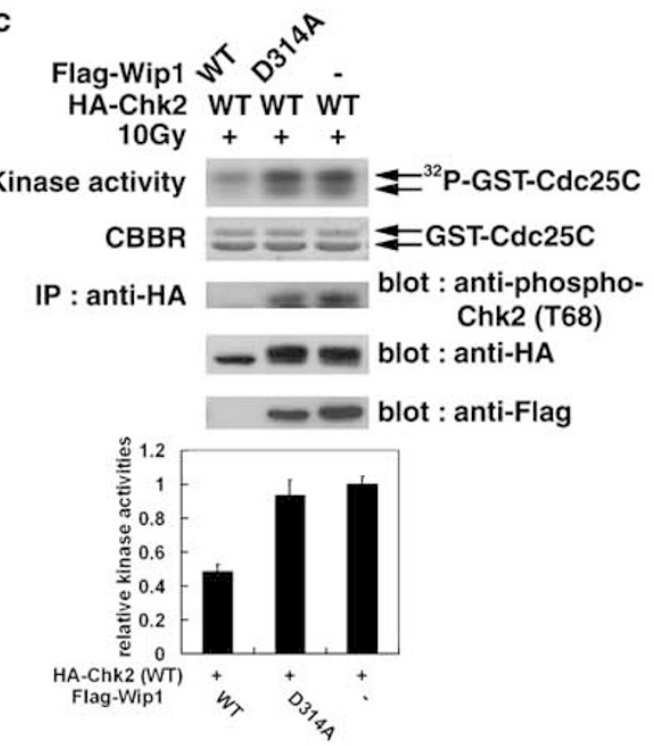

and purified using glutathione-Sepharose beads. Purified GST-Wip1 (WT), but not GST-Wip1 (D314A), exhibited phosphatase activity toward $p$-nitrophenyl phosphate ( $p N P P$ ) (data not shown), confirming that each functions as expected with respect to phosphatase activity. In these assays, it was found that the pNPP phosphatase activity of purified GSTWip1 (WT) is $\mathrm{Mg}^{2+}$ dependent (data not shown), consistent with previous reports that Wip1 displays characteristics of the PP2C family of protein phosphatases ${ }^{25}$ These purified GST fusion proteins were subjected to an in vitro phosphatase assay using Thr68- and Thr387-phosphorylated HA-Chk2 as a substrate (see Materials and Methods). GST-Wip1 (WT), but not GST-Wip1 (D314A), dephosphorylated Thr68 in Chk2 in vitro (Figure $3 \mathrm{a}$ ), and this activity was time dependent and $\mathrm{Mg}^{2+}$ dependent (data not shown), characteristic of Wip1. On the other hand, GST-Wip1 (WT) failed to dephosphorylate Thr387 in Chk2 in vitro (Figure 3a). These results are consistent with the idea that Wip1 can dephosphorylate the phosphorylated-Thr68 in Chk2 induced by $\gamma$-irradiation or ectopic overexpression of Chk2, and that Thr68-phosphorylation of Chk2 is a prerequisite event for (trans-)phosphorylating Thr387 (and possibly Thr383) in Chk2 (see Figure 2c). ${ }^{31-34}$ We also examined whether Wip1 could dephosphorylate Ser19, Ser33/35, Thr432, and Ser516 in Chk2. As shown in Figure 3a, GST-Wip1 (WT), but not GST-Wip1 (D314A), dephosphorylated-Ser19, -Ser33/35, -Thr432, but not Ser516 in Chk2 in vitro. The results of our in vitro phosphatase assays (Figure 3a) (data not shown), ${ }^{24}$ are summarized in Table 1. As shown, Wip1 appears to dephosphorylate preferably a phosphorylated $\mathrm{S}$ or $\mathrm{T}$ followed by a glutamine $(\mathrm{Q})$ in vitro.

\section{Inhibition of Chk2 kinase activity by Wip1- mediated dephosphorylation of Thr68 in Chk2}

It can be assumed that dephosphorylation of the phosphorylated-Thr68 in Chk2 by Wip1 may result in the inhibition of Chk2 kinase activity. To investigate this hypothesis, HA-Chk2 activated by ectopic overexpression and/or $\gamma$-irradiation was

Figure 3 Dephosphorylation of phosphorylated-Thr68 in Chk2 and inhibition of Chk2 kinase activity by Wip1 in vitro. (a) Phosphorylated-HA-Chk2 on Ser19, Ser33/35, Thr68, Thr387, Thr432, or Ser516 was prepared from $\gamma$-irradiated 293T cells overexpressing HA-Chk2 (WT), followed by anti-HA immunoprecipitation. Reaction was initiated by the addition of an equal amount $(1 \mu \mathrm{g})$ of the respective GST fusion proteins, and an in vitro phosphatase assay was performed (see Materials and Methods). Samples prepared after phosphatase reaction were immunoblotted with antiphospho-Chk2 (Ser19, Ser33/35, Thr68, Thr387, Thr432, or Ser516) or anti-HA antibodies, respectively. (b) Phosphorylated-HA-Chk2 on Thr68 was immunoprecipitated and treated with purified GSTWip1 (WT) or GST-Wip1 (D314A) in vitro. Subsequently, two-third of each sample was subjected to an in vitro kinase (IVK) assay using GST-Cdc25C as a substrate and the rest was immunoblotted with either antiphospho-Chk2 (Thr68) or anti-HA antibodies. A histogram shows quantification of Chk2 kinase activities toward GST-Cdc25C. Data are expressed as the means \pm S.D. in triplicate assays from a representative experiment of three. The arrows indicate the positions of GST-Cdc25C. (c) 293T cells expressing HA-Chk2 along with either Flag-Wip1 (WT) or Flag-Wip1 (D314A) were subjected to $\gamma$-irradiation. Anti-HAimmunoprecipitates of WCLs from the respective transfectants were subjected to an IVK assay using GST-Cdc25C as a substrate. WCLs were subjected to antiphospho-Chk2 (Thr68)-, anti-HA-, or anti-Flag-immunoblotting, as indicated. A histogram shows quantification of Chk2 kinase activity toward GST-Cdc25C. Data are expressed as the mean \pm S.D. in triplicate assays from a representative experiment of three. The arrows indicate the positions of GST-Cdc25C 
Table 1 Selectivity of dephosphorylation of phosphorylated serine and/or threonine residue by Wip1 in vitro

\begin{tabular}{|c|c|c|c|c|c|c|c|c|c|c|c|c|c|}
\hline & & & & & & & & & & & & & $\begin{array}{l}\text { Dephosphorylation } \\
\text { by Wip1 in vitro }\end{array}$ \\
\hline \multirow[t]{7}{*}{ Chk2 } & S19 & G & $\mathrm{S}$ & S & A & C & $\mathrm{S}^{\mathrm{a}}$ & $\underline{\mathrm{Q}}$ & $\mathrm{P}$ & $\mathrm{H}$ & G & S & + \\
\hline & S33/S35 & $\mathrm{G}$ & $S$ & $\mathrm{~S}$ & $S^{a}$ & $\underline{Q}$ & $\mathrm{~S}^{\mathrm{a}}$ & $\underline{\bar{Q}}$ & G & 1 & $S$ & $\mathrm{~S}$ & + \\
\hline & T68 & $\mathrm{L}$ & $E$ & $\mathrm{~T}$ & V & $\overline{\mathrm{S}}$ & $\mathrm{T}^{\mathrm{a}}$ & $\underline{\bar{Q}}$ & $E$ & $\mathrm{~L}$ & $\mathrm{Y}$ & $\mathrm{S}$ & + \\
\hline & T383 & $\overline{\mathrm{T}}$ & $\bar{S}$ & $\mathrm{~L}$ & M & $\mathrm{R}$ & $\mathrm{T}^{\mathrm{a}}$ & $\overline{\mathrm{L}}$ & $\bar{C}$ & $\mathrm{G}$ & $\mathrm{T}$ & $\mathrm{P}$ & ND \\
\hline & T387 & $\mathrm{R}$ & $\mathrm{T}$ & $\mathrm{L}$ & C & G & $\mathrm{T}^{\mathrm{a}}$ & $\mathrm{P}$ & $\mathrm{T}$ & $\mathrm{Y}$ & $L$ & A & - \\
\hline & T432 & $\mathrm{F}$ & $S$ & $E$ & $\mathrm{H}$ & $\mathrm{R}$ & $\mathrm{T}^{\mathrm{a}}$ & $\underline{\mathrm{Q}}$ & V & $\mathrm{S}$ & $\mathrm{L}$ & $\mathrm{K}$ & + \\
\hline & S516 & V & L & A & $Q$ & $\mathrm{P}$ & $S^{a}$ & $\overline{\bar{T}}$ & $\mathrm{~S}$ & $\mathrm{R}$ & $\mathrm{K}$ & $\mathrm{R}$ & - \\
\hline \multirow[t]{2}{*}{ Chk1 } & S317 & $\mathrm{L}$ & $\mathrm{K}$ & $\mathrm{Y}$ & $\widehat{S}$ & $S$ & $\mathrm{~S}^{\mathrm{a}}$ & $\underline{\mathrm{Q}}$ & $\mathrm{P}$ & $\mathrm{E}$ & $\mathrm{P}$ & $\mathrm{R}$ & $++^{\mathrm{b}, \mathrm{c}}$ \\
\hline & S345 & $Q$ & G & I & $\mathrm{S}$ & $\mathrm{F}$ & $\mathrm{S}^{\mathrm{a}}$ & $\overline{\mathrm{Q}}$ & $\mathrm{P}$ & $\mathrm{T}$ & C & $\mathrm{P}$ & $++^{\mathrm{b}, \mathrm{c}}$ \\
\hline Cdc25C & S216 & $\mathrm{L}$ & $\mathrm{Y}$ & $\mathrm{R}$ & $\mathrm{S}$ & $\mathrm{P}$ & $\mathrm{S}^{\mathrm{a}}$ & $\overline{\mathrm{M}}$ & $\mathrm{P}$ & $E$ & $\mathrm{~N}$ & $\mathrm{~L}$ & $-{ }^{b, d}$ \\
\hline & $\mathrm{S} 15$ & $\mathrm{~V}$ & $E$ & $\mathrm{P}$ & $\mathrm{P}$ & $\mathrm{L}$ & $\mathrm{S}^{\mathrm{a}}$ & $\underline{Q}$ & $E$ & $\overline{\mathrm{T}}$ & $\mathrm{F}$ & $\bar{S}$ & $t^{\mathrm{b}, \mathrm{c}}$ \\
\hline & $\mathrm{S} 20$ & $S$ & $\mathrm{Q}$ & $E$ & $\mathrm{~T}$ & $\mathrm{~F}$ & $S^{a}$ & $\overline{\mathrm{D}}$ & $\bar{L}$ & W & $\mathrm{K}$ & $\mathrm{L}$ & ${ }^{c}{ }^{c}$ \\
\hline & S33 & $E$ & $\mathrm{~N}$ & $\mathrm{~N}$ & $\mathrm{~V}$ & L & $\mathrm{S}^{\mathrm{a}}$ & $\mathrm{P}$ & $\mathrm{L}$ & $\mathrm{P}$ & $\mathrm{S}$ & $\mathrm{Q}$ & ${ }_{-}^{\mathrm{e}}$ \\
\hline & S46 & D & D & $\mathrm{L}$ & M & $\mathrm{L}$ & $S^{a}$ & $\mathrm{P}$ & D & D & I & $\mathrm{E}$ & $-^{\mathrm{c}, \mathrm{e}}$ \\
\hline p38 & T180 & $\mathrm{T}$ & $\mathrm{D}$ & $\mathrm{D}$ & $\mathrm{E}$ & $\mathrm{M}$ & $\mathrm{T}^{\mathrm{a}}$ & $\mathrm{G}$ & $\mathrm{Y}$ & $\mathrm{V}$ & A & $\bar{T}$ & $+^{e}$ \\
\hline UNG2 & T6 & $\mathrm{M}$ & I & G & Q & $\mathrm{K}$ & $\mathrm{T}^{\mathrm{a}}$ & $\underline{\underline{L}}$ & $\mathrm{Y}$ & $\mathrm{S}$ & $\mathrm{F}$ & $\mathrm{F}$ & $+^{f}$ \\
\hline
\end{tabular}

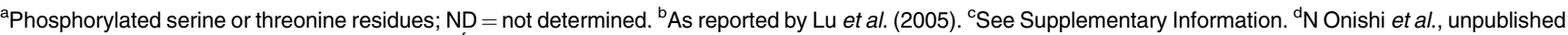
data. ${ }^{e}$ As reported by Takekawa et al. (2000). ${ }^{\dagger}$ As reported by Lu et al. (2004). Glutamine residues following phosphorylated serine or threonine residues were underlined.

immunoprecipitated with anti-HA antibody, treated with purified GST-Wip1 (WT) or GST-Wip1 (D314A), and was subjected to an in vitro kinase assay using GST-Cdc25C (a.a. 200-256) as a substrate (see Materials and Methods). However, it is possible that GST-Wip1, associated with HAChk2, may exhibit phosphatase activities toward phosphorylated-GST-Cdc25C by HA-Chk2 in this assay. It was found that GST-Wip1 (WT) failed to dephosphorylate the phosphorylated-GST-Cdc25C by HA-Chk2 in vitro (data not shown), indicating that phosphorylated-GST-Cdc25C is not a substrate of Wip1 at least in vitro. Considering the finding that Wip1 dephosphorylates the phosphorylated-Ser33/35 and -Thr68, but not phosphorylated-Thr387 in Chk2 in vitro (Figure $3 \mathrm{a}$ ), the result also suggests the substrate specificity of Wip1. Interestingly, incubation of immunoprecipitated HA-Chk2 (activated by its ectopic overexpression and/or $\gamma$-irradiation) with GST-Wip1 (WT), but not GST-Wip1 (D314A), resulted in a drastic inhibition of Chk2 kinase activity toward GST-Cdc25C in vitro (Figure 3b). Furthermore, coexpression of Flag-Wip1 (WT), but not Flag-Wip1 (D314A) in $293 \mathrm{~T}$ cells, resulted in a drastic inhibition of Chk2 kinase activity in vitro (Figure 3c), confirming that Wip1 inhibits Chk2 kinase activity by dephosphorylating the phosphorylatedThr68 in Chk2.

\section{Abnormally sustained Thr68 phosphorylation and kinase activity of Chk2 by inhibition of Wip1 expression}

Considering our results indicating that Wip1 dephosphorylates and inactivates Chk2, it is likely that Wip1 acts as a negative regulator of Chk2 during DNA damage responses. To test such a possibility, we performed an RNAi experiment with Wip1 siRNAs or controlsiRNAs and monitored the effects of inhibition of Wip1 expression on the extent of Thr68phosphorylation and kinase activity of Chk2 following $\gamma$-irradiation. In this experiment, p53-proficient MCF7 and
HCT116 cells were utilized (see Materials and Methods). At 3 days after transfection, expression levels of Wip1 protein in cells transfected with Wip1 siRNAs decreased drastically compared to cells transfected with control siRNAs, as assayed by immunoblot analysis (Figure 4a, data not shown). In cells transfected with control siRNAs, Thr68-phosphorylation and kinase activity of Chk2 increased following $\gamma$-irradiation and decreased rapidly thereafter, while increased Thr68-phosphorylation and kinase activity of Chk2 were abnormally sustained in cells transfected with Wip1 siRNAs following $\gamma$-irradiation (Figure $4 a$, data not shown). A sustained electrophoretic mobility shift of Chk2 was also observed in cells transfected with Wip1 siRNAs following $\gamma$ irradiation compared to cells transfected with control siRNAs. These results support the notion that Wip1 induced by DNA damage acts as a negative regulator of Chk2 in the DNA damage response.

Since Wip1 was identified as 'wild-type p53-inducible phosphatase 1, ${ }^{25}$ we next examined the effect of inhibition of p53 expression by p53 siRNA on the extent of $\gamma$-irradiationinduced expression of Wip1 and Thr68-phosphorylation of Chk2 (see Materials and Methods). As shown in Figure 4b, in MCF7 cells transfected with controlsiRNAs, upon $\gamma$-irradiation apparent induction of p53 proteins (reached maximal levels within $2 \mathrm{~h}$ ) followed by induction of Wip1 proteins (reached maximal levels between 2 and $4 \mathrm{~h}$ ) were observed, while transfection of MCF7 cells with p53 siRNAs resulted in inhibition of induction of both p53 and Wip1 proteins following $\gamma$-irradiation. Consistent with suppressed expression of Wip1 proteins in MCF7 cells transfected with p53 siRNAs following $\gamma$-irradiation, increased Thr68-phosphorylation of Chk2 was abnormally sustained in cells transfected with p53 siRNAs following $\gamma$-irradiation compared to cells transfected with control siRNAs (Figure 4b). Thus, the result indicates that p53 contributes to dephosphorylation of the phosphorylatedThr68 in Chk2 at later points (4-8h) of DNA damage-induced responses by regulating the induction of Wip1 proteins following $\gamma$-irradiation. 
a
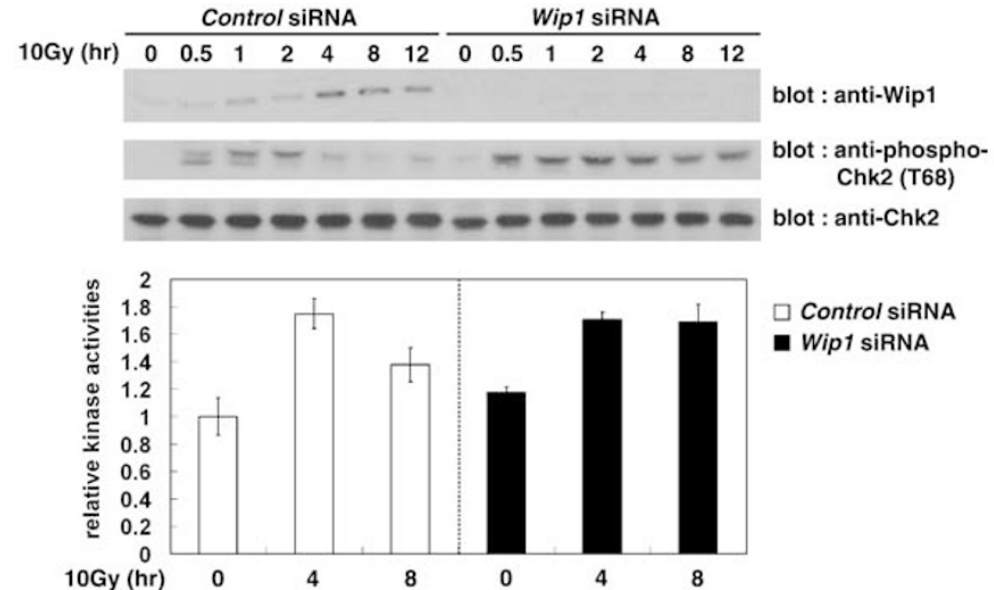

b
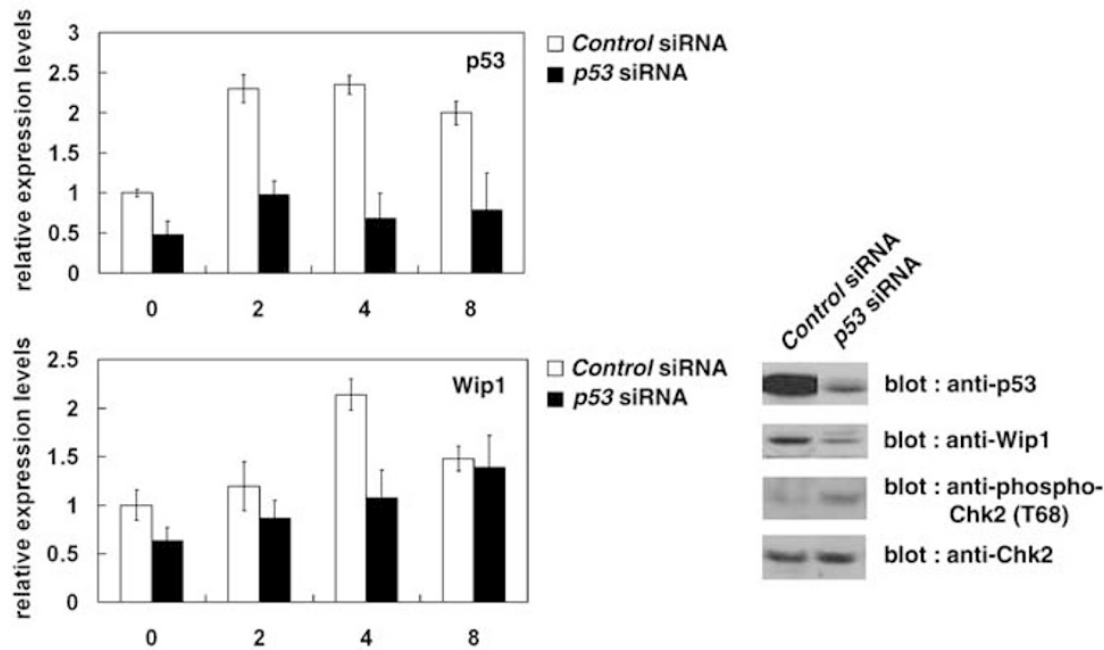
Chk2 (T68)

- blot : anti-Chk2

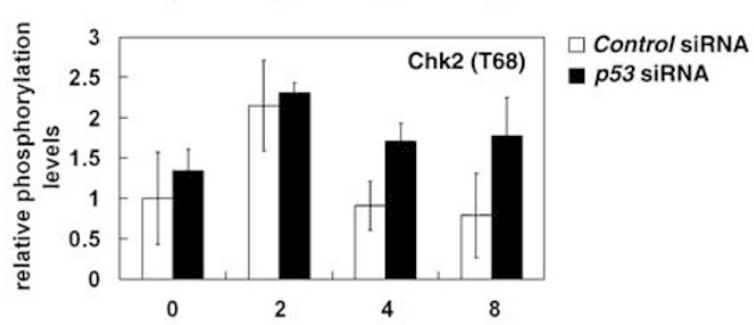

Figure 4 Sustained Thr68 phosphorylation and kinase activity of Chk2 by Wip1 siRNAs-mediated inhibition of Wip1 expression in response to DNA damage. (a) MCF7 cells were transfected with either Wip1 siRNAs or control siRNAs (see Materials and Methods). At 3 days after transfection, cells were exposed to $\gamma$-irradiation. At the indicated time points, the respective WCLs were subjected to immunoblotting with antiphospho-Chk2 (Thr68) and anti-Chk2 as indicated. At the indicated time points (0, 4 , and $8 \mathrm{~h}$ ), anti-Chk2 immunoprecipitates of the respective WCLs were subjected to an IVK (see Materials and Methods). A histogram shows quantification of Chk2 kinase activity toward GST-Cdc25C. Data are expressed as the means \pm S.D. of relative kinase activities (relative to the level in nonirradiated cells with control siRNA) in three independent experiments. (b) MCF7 cells were transfected with either p53 siRNAs or control siRNAs. At 4 days after transfection, cells were exposed to $10 \mathrm{~Gy} \gamma$ irradiation. At the indicated time points after $\gamma$-irradiation, WCLs from the respective transfectants were subjected to immunoblotting with anti-p53, anti-Wip1, antiphospho-Chk2 (Thr68), or anti-Chk2 antibodies, and the intensity of the respective bands was quantified. Histograms show quantification of expression levels of p53 and Wip1 proteins, respectively (upper, middle panels). Relative levels of Thr68-phosphorylation of Chk2 (lower panel) were determined by normalization with levels of Chk2 proteins in the respective samples. Data are expressed as the mean \pm S.D. (relative to the levels in nonirradiated cells with control siRNA) in three independent experiments. Representative results (at $4 \mathrm{~h}$ after $\gamma$-irradiation) of the immunoblots are also indicated

\section{Antagonistic effect of Wip1 on Chk2-dependent apoptosis}

To understand the role of Wip1 in regulating cellular function, we monitored the effect of inhibition of Wip1 expression on the extent of $\gamma$-irradiation-induced apoptosis by TUNEL assays (see Materials and Methods). As shown in Figure 5a, MCF7 cells transfected with Wip1 siRNAs, but not control siRNAs, exhibited remarkably enhanced apoptosis following $\gamma$-irradiation, indicating that Wip1 negatively regulates $\gamma$-irradiationinduced apoptosis by dephosphorylating and inactivating Chk2. Similar results were obtained when p53-proficient 
HCT116 cells, transfected with control siRNAs or Wip1 siRNAs, were subjected to TUNEL assays following $\gamma$ irradiation (data not shown). Furthermore, $\gamma$-irradiationinduced apoptosis was inhibited by Chk2 siRNAs (data not

a

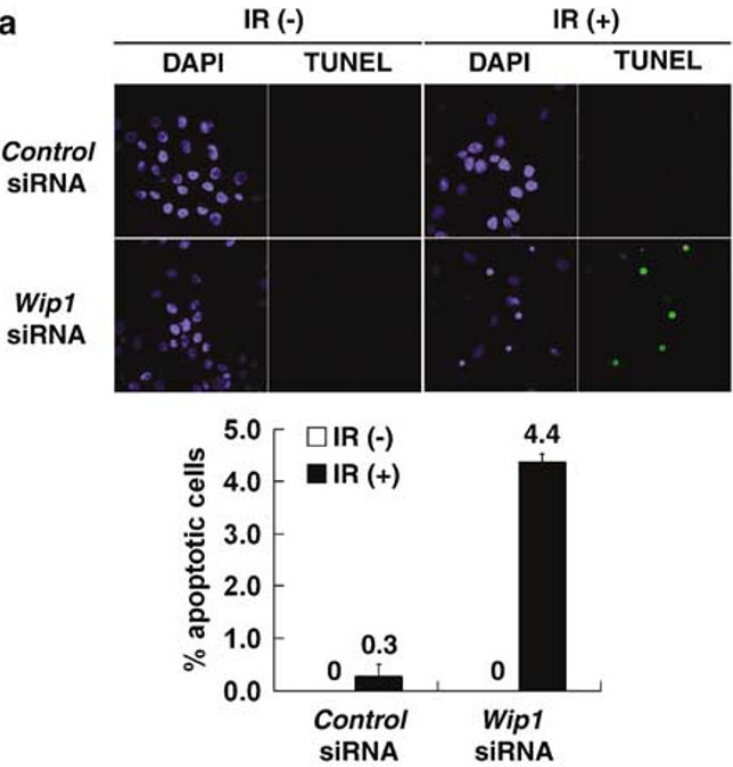

b
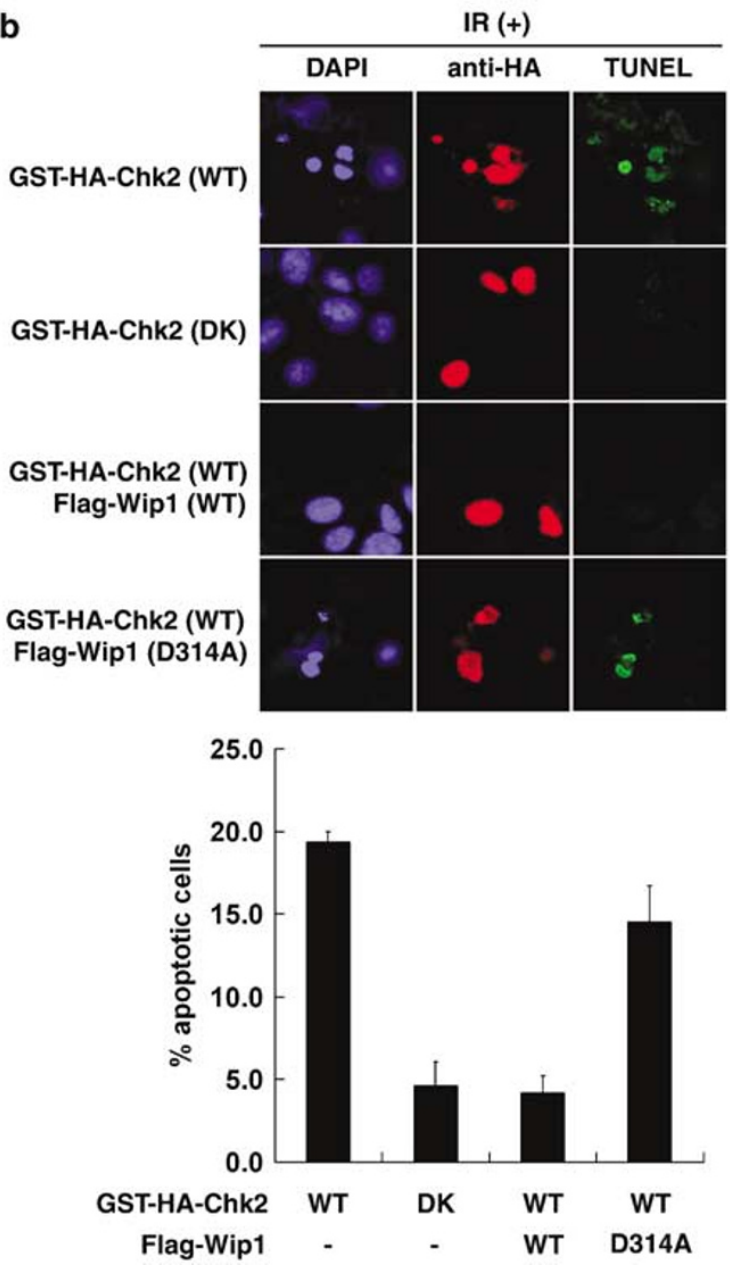

shown). Moreover, it was found that ectopic expression of HA-Chk2 (WT) by itself in MCF7 cells enhanced $\gamma$-irradiationinduced apoptosis, but was inhibited by coexpression of FlagWip1 (WT), but not Flag-Wip1 (D314A), indicating that Wip1 antagonizes Chk2-mediated apoptosis in a phosphatase activity-dependent manner (Figure $5 \mathrm{~b}$ ). It has been reported that phosphorylation of Ser516 in Chk2 is required for radiation-induced apoptosis. ${ }^{35}$ Thus, the inhibition of Chk2mediated apoptosis by Wip1 following $\gamma$-irradiation can be explained by our observation that ectopic coexpression of Wip1 inhibits phosphorylation of Ser516 in Chk2 (Figure 2c). Taken together, these results indicate that enhanced apoptosis induced by Wip1 siRNA is dependent both on $\gamma$ irradiation and on Chk2, and that Wip1 acts as a negative regulator during $\gamma$-irradiation-induced apoptosis. In this respect, it is of interest to note that fibroblasts from Wip1null embryos exhibit a decreased proliferation rate. ${ }^{36}$ It has been reported that Wip1 contributes to suppression of UVirradiation-induced apoptosis by dephosphorylating and inactivating $\mathrm{p} 38 .{ }^{24}$ However, $\gamma$-irradiation-induced apoptosis of MCF7 cells transfected with Wip1 siRNAs was unaffected in the absence or presence of the specific inhibitor of p38, SB203580 (data not shown).

Chk2 mutations have been found in patients having a variant form of the familial multicancer $\mathrm{Li}-$ Fraumeni syndrome, and Chk2 kinase is considered to be a tumour suppressor. ${ }^{7,8,37}$ In contrast, Wip1 phosphatase is considered to be an oncogenic protein, on the basis of the findings that the gene encoding Wip1 (PPM1D) is amplified in human breast cancers, ${ }^{26-28}$ and that disruption of the Wip1 gene activates p53 and p16 ${ }^{\text {Ink4a }}-p 19^{\text {Arf }}$ pathway via p38 MAPK signalling, resulting in the suppression of in vitro transformation of MEFs and of in vivo tumorigenesis by oncogenes. ${ }^{38,39}$ It has also been reported that following DNA damage ATM phosphorylates Chk2 at Thr68, an event critical for the activation of Chk2. ${ }^{9-13}$ Here we show that Wip1 dephosphorylates Thr68 in Chk2 both in vivo and in vitro (Figures 2 and 3), and may act as a negative regulator of Chk2 (Figures $4 b$ and 5). It has been reported that Ptc2 and Ptc3, two members of the PP2C family, bind to Rad53 and inactivate Rad53-dependent pathways in S. cerevisiae. ${ }^{21}$ Considering our results, it is likely that Ptc2 and Ptc3 inactivate Rad53 by dephosphorylating it. Furthermore, we provide evidence suggesting that Wip1 may

Figure 5 Antagonistic function of Wip1 on Chk2-dependent apoptosis. (a) MCF7 cells were transfected with either Wip1 siRNAs or control siRNAs. At 3 days after transfection, cells were nonirradiated or exposed to $20 \mathrm{~Gy} \gamma$-irradiation, and cultured for $36 \mathrm{~h}$. Cellular apoptosis was then examined by TUNEL assays (see Materials and Methods). A histogram shows the fraction of apoptotic cells determined by dividing the number of TUNEL-positive cells by the total number of cells counted. About 1000 cells from three to four randomly chosen fields were counted. Decreased expression levels of Wip1 in cells treated with Wip1 siRNAs were confirmed by anti-Wip1-immunoblotting (data not shown). (b) GST-HAChk2 (WT), GST-HA-Chk2 (DK), Flag-Wip1 (WT), or Flag-Wip1 (D314A) in combination were expressed transiently in MCF7 cells as indicated. After transfection, cells were exposed to $20 \mathrm{~Gy} \gamma$-irradiation, and cultured for $36 \mathrm{~h}$. Cellular apoptosis was examined by TUNEL assays (see Materials and Methods). A histogram shows the fraction of apoptotic cells determined by dividing the number of TUNEL-positive cells by the total number of anti-HApositive cells. About 1000 cells from three to four randomly chosen fields were counted. Expression of GST-HA-Chk2 and Flag-Wip1 proteins was assessed by immunostaining with anti-HA and anti-Flag (data not shown) antibodies 
negatively regulate $\gamma$-irradiation-induced apoptosis by dephosphorylating and inactivating Chk2 (Figures 4 and 5). However, at present we cannot rule out the possibility that Wip1 may dephosphorylate and inactivate ATM or other proteins, thereby inhibiting Chk2 function. Interestingly, it has been recently reported that Wip1 dephosphorylates the nuclear form of uracil DNA glycosylase (UNG2) and Chk1, thereby suppressing BER and intra-S and G2/M checkpoint regulation, respectively. ${ }^{30,40}$ In the case of UNG2 and p38, phosphorylation sites on these molecules, which can be targets for Wip1-mediated dephosphorylation, reveal consensus sequences 'phospho-T-X-phospho-Tyr ( $Y$ ) (or phospho-T-X-Y, X: optional a.a.)'. ${ }^{41}$ In this respect, it is important to note that our in vitro evidence as well as previous report ${ }^{40}$ indicate the presence of additional target sequences for Wip1, which are 'phospho-S-Q' or 'phospho-T-Q', well-known fingerprints of ATM kinase (see Table 1). Future study to identify a substrate(s) for Wip1 in addition to phosphorylatedChk2, -Chk1, -p38, ${ }^{24}$ and -UNG2 ${ }^{30}$ may contribute to our understanding of the roles of Wip1 during DNA damageinduced cellular responses.

\section{Materials and Methods}

\section{Plasmid constructions}

The human Chk2 coding region was amplified by PCR using human placenta CDNA as a template, and subcloned into the mammalian expression vector pcDNA3 (Invitrogen). The mutant Chk2 (T68A) was generated by replacing Thr68 with Ala using the Transformer TM SiteDirected mutagenesis kit (Clontech). The kinase-dead mutant of Chk2 (DK) replaces Lys249 with Arg and was created by PCR. A PCR-based procedure was employed to attach an $\mathrm{HA}$ tag at the C-terminal end of Chk2; to generate the expression vectors, pcDNA-Chk2 (WT)-HA, pcDNAChk2 (T68A)-HA, pcDNA-Chk2 (DK)-HA, and pEBG-Chk2 (encoding GST-HA-Chk2) were constructed to attach GST and HA tags at the $\mathrm{N}$ - and C-terminal ends of Chk2, respectively. pGEX-3X-Chk2, encoding GSTChk2 fusion proteins, was constructed to attach GST tag at the N-terminal end of Chk2; pGEX-3X-Cdc25C, encoding GST-Cdc25C (a.a. 200-256 of human $\mathrm{Cdc} 25 \mathrm{C}$ ), was constructed by subcloning of the PCR amplified Cdc25C cDNA fragment into the pGEX-3X to generate GST-Cdc25C. pCMV-Wip1 (WT), and pCMV-Wip1 (D314A), encoding the wild-type and phosphatase inactive mutant of Wip1, respectively, were constructed as described previously. ${ }^{24}$ A PCR-based procedure was employed to attach a FLAG-tag sequence at the C-terminal end of Wip1 to generate pcDNAWip1 (WT)-FLAG and pcDNA-Wip1 (D314A)-FLAG. pGEX-5X-Wip1 (WT) and pGEX-5X-Wip1 (D314A), encoding GST-Wip1 (WT) and GST-Wip1 (D314A), respectively, were constructed as described previously. ${ }^{24}$ pcDNA-PP2C $\alpha 2(W T)-F L A G$, encoding the wild-type Flag-PP2C $\alpha 2$, was constructed as described previously. ${ }^{23}$ pcDNA-Chk1-myc, encoding the wild-type Chk1 of mouse origin, was a gift from Noboru Motoyama (National Institute for Longevity Sciences, Japan).

\section{Antibodies, cells, and DNA transfection}

The following antibodies were used: mouse monoclonal antibody (MoAb) M2 (Eastman Kodak) recognizes the Flag peptide sequence (DYKDDDDK). Mouse MoAb 12CA5 (Boehringer Mannheim) and rat MoAb 3F10 (Roche) recognize the peptide sequence (YPYDVPDYA) derived from the human influenza HA protein. Mouse MoAb 9E10 (Santa
Cruz) recognize the peptide sequence (EQKLISEEDL) derived from human c-myc protein. Rabbit polyclonal anti-Chk2 antibody was raised against peptides corresponding to a.a. 523-543 of human Chk2. Rabbit polyclonal anti-Wip1 antibody was raised against GST-Wip1 (a.a. 1-458). Mouse monoclonal anti-Wip1 (WC 10) antibody was from Trevigen. Mouse monoclonal anti-p53 (DO-1) antibody was from Santa Cruz. Rabbit polyclonal anti-phospho-Chk1 (Ser317 and Ser345) antibodies, antiphospho-Chk2 (Ser19, Ser33/35, Thr68, Thr387, Thr432, and Ser516) antibodies, and anti-phospho-p53 (Ser15, Ser20, and Ser46) antibodies were purchased from Cell Signaling. Alexa Fluor 546 (goat anti-mouse IgG, red) and Alexa Fluor 488 (goat anti-rat IgG, green) were purchased from Molecular Probes. SB203580, a specific inhibitor of p38 MAP kinase (p38 $\alpha, \mathrm{p} 38 \beta$, and p38 $\beta 2$ ), was from Promega. HEK293T (293T), MCF7 cells were maintained in Dulbecco's modified Eagle's medium (Nissui) supplemented with $10 \%(\mathrm{v} / \mathrm{v})$ foetal calf serum (FCS). HCT116 cells were maintained in McCoy's 5a medium (GibcoBRL) supplemented with $10 \%$ (v/v) FCS. It should be noted that 293T cells bear p53 inactivated by adenovirus E1B and SV40 T-antigen, while MCF7 and HCT116 cells are p53-proficient breast adenocarcinoma and colorectal carcinoma cells, respectively. Transient cDNA transfection into cells was performed using the calcium phosphate method ${ }^{3}$ or Lipofectamine Reagent, PLUS Reagent, and Lipofectamine 2000 Reagent (GibcoBRL) according to the manufacturer's instructions.

\section{Preparation of cell lysates and co-(immuno) precipitation analysis}

Transfected cells were solubilized with lysis buffer $(50 \mathrm{mM}$ Tris- $\mathrm{HCl}$ (pH 7.4), 0.5\% (v/v) NP-40, $150 \mathrm{mM} \mathrm{NaCl}, 5 \mathrm{mM}$ EDTA, $50 \mathrm{mM} \mathrm{NaF}, 1 \mathrm{mM}$ $\mathrm{Na}_{3} \mathrm{VO}_{4}, 1 \mathrm{mM}$ phenylmethyl sulphonyl fluoride (PMSF), $10 \mu \mathrm{g} / \mathrm{ml}$ aprotinin), and cell lysates were prepared by centrifugation at $12000 \times g$ for $15 \mathrm{~min}$ at $4^{\circ} \mathrm{C}$. Subsequently, the cell lysates were subjected to pull-down assay/immunoblot analysis or co-(immuno) precipitation/immunoblot analysis. For co-(immuno) precipitation analysis, the cell lysates were precleared with protein A-Sepharose (Amersham Pharmacia Biotech) for $1 \mathrm{~h}$ at $4^{\circ} \mathrm{C}$. The precleared supernatants were then co-(immuno) precipitated with glutathione-Sepharose beads (Amersham Pharmacia Biotech) or with anti-HA antibody conjugated to protein ASepharose beads for $2 \mathrm{~h}$ at $4^{\circ} \mathrm{C}$. The resultant precipitates were washed five times with lysis buffer, and eluted with Laemmli sample buffer.

\section{Expression and purification of GST fusion proteins}

The plasmids encoding the GST fusion proteins, GST-Chk2 (WT), GSTWip1 (WT), GST-Wip1 (D314A), and GST-Cdc25C (a.a. 200-256), were constructed using the pGEX plasmids (Amersham Pharmacia Biotech). GST fusion proteins expressed in $E$. coli $\mathrm{DH} 5 \alpha$ were extracted with phosphate-buffered saline (PBS) containing 1\% (v/v) Triton X-100, $1 \mathrm{mM}$ EDTA, $1 \mathrm{mM} \mathrm{PMSF}, 10 \mu \mathrm{g} / \mathrm{ml}$ leupeptin, and $10 \mu \mathrm{g} / \mathrm{ml}$ aprotinin, and were isolated with glutathione-Sepharose beads. To further purify GST-Wip1 (WT), GST-Wip1 (D314A), and GST-Cdc25C for phosphatase and kinase assays, fusion proteins were eluted from beads by incubating with $25 \mathrm{mM}$ glutathione (reduced), followed by dialysis prior to use.

\section{Pull-down assay and immunoblot analysis}

The cell lysates were precleared with glutathione-Sepharose for $1 \mathrm{~h}$ at $4^{\circ} \mathrm{C}$. The precleared supernatant was then incubated with the respective GST fusion proteins conjugated with glutathione-Sepharose beads for $1 \mathrm{~h}$ 
at $4^{\circ} \mathrm{C}$, washed five times with lysis buffer, and eluted with Laemmli sample buffer. Precipitates either from the pull-down assay or whole-cell lysates were separated by SDS-PAGE (10\% PAG), and transferred onto PVDF membrane filters (Immobilon P, Millipore). The membranes were immunoblotted with the respective antibodies, and bound antibodies were visualized with HRP-conjugated antibodies against mouse or rabbit IgGs (Bio-Rad) using the chemiluminescence reagent (Renaissance, NEN). Quantification of the immunoblots was performed by densitometric scanning of the film using an Image Analysis system with NIH Image 1.62 software.

\section{In vitro phosphatase assay and kinase assays}

To prepare phosphorylated-HA-Chk2 (WT), 293T cells were transfected with the expression vector encoding HA-Chk2 (WT). For in vitro kinase assay, $24 \mathrm{~h}$ after transfection, cells were exposed to $10 \mathrm{~Gy} \gamma$-irradiation, and harvested $1 \mathrm{~h}$ later. Phosphorylated-HA-Chk2 (WT) was immunoprecipitated with anti-HA antibody, washed five times with lysis buffer, and resuspended in $50 \mu \mathrm{l}$ phosphatase buffer $(50 \mathrm{mM}$ Tris- $\mathrm{HCl}(\mathrm{pH} 7.5)$, $30 \mathrm{mM} \mathrm{MgCl}_{2}, 1 \mathrm{mg} / \mathrm{ml}$ bovine serum albumin, 0.05\% 2-mercaptoethanol). The in vitro phosphatase reaction was initiated by addition of purified GSTWip1 (WT) or GST-Wip1 (D314A), and allowed to incubate for $1 \mathrm{~h}$ at $30^{\circ} \mathrm{C}$. Samples were separated by SDS-PAGE ( $9 \% \mathrm{PAG})$, and transferred onto PVDF membrane filters. Immunoblot analysis was performed with antiphospho-Chk2 (Ser19, Ser33/35, Thr68, Thr387, Thr432, or Ser516) antibody to monitor the extent of Ser19, Ser33/35, Thr68, Thr387, Thr432, or Ser516-phosphorylation in Chk2 in the respective samples. The amounts of phosphorylated HA-tagged Chk2 (WT) were assessed by anti$\mathrm{HA}$ immunoblot analysis. Kinase activities of Chk2 after treatment with bacterial expressed GST-Wip1 (WT) or GST-Wip1 (D314A) in vitro were determined as follows: samples treated with either GST-Wip1 (WT) or GST-Wip1 (D314A) were washed once with kinase buffer $(10 \mathrm{mM}$ HEPES- $\mathrm{NaOH}$ (pH 7.5), $5 \mathrm{mM} \mathrm{MgCl}, 2 \mathrm{mM}$ DTT), resuspended in $30 \mu$ of the kinase buffer containing $2 \mu \mathrm{g}$ GST-Cdc25C (a.a. 200-256), and $15 \mu \mathrm{Ci}$ of $\left[\gamma^{32} \mathrm{P}\right]$ ATP $(5000 \mathrm{Ci} / \mathrm{mmol}$; Amersham), and incubated for $30 \mathrm{~min}$ at $30^{\circ} \mathrm{C}$. The reactions were terminated by the addition of Laemmli sample buffer, separated by SDS-PAGE (12\% PAG), and were subjected to autoradiography. Kinase activities of Chk2 in cells coexpressing FlagWip1 (WT) or Flag-Wip1 (D314A) or in cells transfected with Wip1 siRNAs or control siRNAs (see below) were also determined similarly using GSTCdc25C (a.a. 200-256) as a substrate following anti-HA or anti-Chk2 immunoprecipitation, respectively.

\section{SiRNA}

The siRNA duplexes were $21 \mathrm{bp}$ including a 2-base deoxynucleotide overhang synthesized by Dharmacon Research. The sequence of the Wip1 siRNA oligo was UUGGCCUUGUGCCUACUAA. The sequence of the p53 siRNA oligo was GCAAUGGAUGAUUUGAUGC. The control siRNA oligo used (Scramble ॥ Duplex) was GCGCGCUUUGUAG GAUUCG. Cells were transfected with siRNA duplexes using GeneSilencer (Gene Therapy Systems) following the manufacturer's instructions.

\section{TUNEL assays}

Cells were transfected with the Wip1 siRNAs or control siRNAs or GST. HA-Chk2 or Flag-Wip1 as described above, subjected to $\gamma$-irradiation (20 Gy), and cultured for $36 \mathrm{~h}$. By using the MEBSTAIN Apoptosis Kit II (MBL), TUNEL assays were performed following the protocol recommended by the manufacturer. In brief, cells were washed with PBS, fixed with $1 \%(\mathrm{w} / \mathrm{v})$ formaldehyde in PBS for $15 \mathrm{~min}$ at $4{ }^{\circ} \mathrm{C}$, and ethanol/acetic acid solution $(2: 1)$ for $5 \mathrm{~min}$ at $-20^{\circ} \mathrm{C}$. DNA fragmentation was nick endlabelled with biotinylated dUTP, mediated by $\operatorname{TdT}$ for $1 \mathrm{~h}$ at $37^{\circ} \mathrm{C}$, and subsequently stained with FITC-conjugated avidin. The nuclei were stained with DAPI or Hoechst. Samples were visualized using an inverted confocal microscope (Zeiss).

\section{Immunofluorescence}

Cells grown on coverslips coated by rat-tail collagen were fixed in $4 \%$ paraformaldehyde/PBS for $15 \mathrm{~min}$ at room temperature and then permeabilized with PBS containing $0.1 \%$ Triton $X-100$ for 15 min at room temperature. After blocking in PBS with 10\% FCS for $30 \mathrm{~min}$, cells were incubated with primary antibodies, anti-FLAG MoAb (M2, 1:500), and/or anti-HA monoclonal Ab (3F10, 1:200), in PBS/10\% FCS for 30 min at room temperature. Cell were washed twice with $\mathrm{PBS}$ and then incubated with secondary antibodies, Alexa Fluor 546 (goat anti-mouse lgG, 1:500) and/or Alexa Fluor 488 (goat anti-rat IgG, 1:200), in PBS/10\% FCS at room temperature for $30 \mathrm{~min}$. After two washes in PBS, the cells were mounted with Pristine Mount (Research Genetics) and analysed with an inverted confocal microscope (Zeiss)

\section{Acknowledgements}

We thank M Lamphier, M Nishita, and M Takao for critically reading the manuscript, and N Motoyama for invaluable research tools. This work was supported by a Grant-in-Aid for Scientific Research on Priority Areas from the Ministry of Education, Culture, Sports, Science and Technology, Japan, by the Yasuda Medical Research Foundation, Nippon Boehringer Ingelheim, Co., Ltd, and Daiichi Pharmaceutical Co., Ltd.

\section{References}

1. Allen JB, Zhou Z, Siede W, Friedberg EC and Elledge SJ (1994) The SAD1/ RAD53 protein kinase controls multiple checkpoints and DNA damage-induced transcription in yeast. Genes Dev. 8: 2401-2415

2. Murakami $\mathrm{H}$ and Okayama $\mathrm{H}$ (1995) A kinase from fission yeast responsible for blocking mitosis in S phase. Nature 374: 817-819

3. Oishi I, Sugiyama S, Otani H, Yamamura H, Nishida Y and Minami Y (1998) A novel Drosophila nuclear protein serine/threonine kinase expressed in the germline during its establishment. Mech. Dev. 71: 49-63

4. Oishi I, Iwai K, Kagohashi Y, Fujimoto H, Kariya K, Kataoka T, Sawa H, Okano $\mathrm{H}$, Otani H, Yamamura H and Minami Y (2001) Critical role of Caenorhabditis elegans homologs of Cds1 (Chk2)-related kinases in meiotic recombination. Mol. Cell. Biol. 21: 1329-1335

5. MacQueen AJ and Villeneuve AM (2001) Nuclear reorganization and homologous chromosome pairing during meiotic prophase require $C$. elegans chk-2. Genes Dev. 15: 1674-1687

6. Matsuoka S, Huang M and Elledge SJ (1998) Linkage of ATM to cell cycle regulation by the Chk2 protein kinase. Science 282: 1893-1897

7. Bartek J, Falck J and Lukas J (2001) CHK2 kinase - a busy messenger. Nat. Rev. Mol. Cell. Biol. 2: 877-886

8. Bartek J and Lukas J (2003) Chk1 and Chk2 kinases in checkpoint control and cancer. Cancer Cell 3: 421-429

9. Brown AL, Lee CH, Schwarz JK, Mitiku N, Piwnica-Worms H and Chung JH (1999) A human Cds1-related kinase that functions downstream of ATM protein in the cellular response to DNA damage. Proc. Natl. Acad. Sci. USA 96: 3745-3750

10. Chaturvedi $P$, Eng WK, Zhu $Y$, Mattern MR, Mishra R, Hurle MR, Zhang $X$, Annan RS, Lu Q, Faucette LF, Scott GF, Li X, Carr SA, Johnson RK, Winkler JD and Zhou BB (1999) Mammalian Chk2 is a downstream effector of the ATMdependent DNA damage checkpoint pathway. Oncogene 18: 4047-4054 
11. Melchionna R, Chen XB, Blasina A and McGowan CH (2000) Threonine 68 is required for radiation-induced phosphorylation and activation of $\mathrm{Cds} 1$. Nat. Cell Biol. 2: 762-765

12. Matsuoka S, Rotman G, Ogawa A, Shiloh Y, Tamai K and Elledge SJ (2000) Ataxia telangiectasia-mutated phosphorylates Chk2 in vivo and in vitro. Proc. Natl. Acad. Sci. USA 97: 10389-10394

13. Ahn JY, Schwarz JK, Piwnica-Worms H and Canman CE (2000) Threonine 68 phosphorylation by ataxia telangiectasia mutated is required for efficient activation of Chk2 in response to ionizing radiation. Cancer Res. 60: 5934-5936

14. Blasina A, de Weyer IV, Laus MC, Luyten WH, Parker AE and McGowan CH (1999) A human homologue of the checkpoint kinase Cds1 directly inhibits Cdc25 phosphatase. Curr. Biol. 9: 1-10

15. Chehab NH, Malikzay A, Appel M and Halazonetis TD (2000) Chk2/hCds1 functions as a DNA damage checkpoint in $\mathrm{G}(1)$ by stabilizing p53. Genes Dev. 14: 278-288

16. Shieh SY, Ahn J, Tamai K, Taya Y and Prives C (2000) The human homologs of checkpoint kinases Chk1 and Cds1 (Chk2) phosphorylate p53 at multiple DNA damage-inducible sites. Genes Dev. 14: 289-300

17. Lee JS, Collins KM, Brown AL, Lee CH and Chung JH (2000) hCds1-mediated phosphorylation of BRCA1 regulates the DNA damage response. Nature 404 201-204

18. Yang S, Kuo C, Bisi JE and Kim MK (2002) PML-dependent apoptosis after DNA damage is regulated by the checkpoint kinase hCds1/Chk2. Nat. Cell Biol. 4: 865-870

19. Stevens C, Smith $L$ and La Thangue NB (2003) Chk2 activates E2F-1 in response to DNA damage. Nat. Cell Biol. 5: 401-409

20. den Elzen NR and O'Connell MJ (2004) Recovery from DNA damage checkpoint arrest by PP1-mediated inhibition of Chk1. EMBO J. 23: 908-918

21. Leroy C, Lee SE, Vaze MB, Ochsenbien F, Guerois R, Haber JE and Marsolier-Kergoat MC (2003) PP2C phosphatases Ptc2 and Ptc3 are required for DNA checkpoint inactivation after a double-strand break. Mol. Cell 11: 827-835

22. Cohen $P$ (1989) The structure and regulation of protein phosphatases. Annu. Rev. Biochem. 58: 453-508

23. Takekawa M, Maeda T and Saito H (1998) Protein phosphatase 2Calpha inhibits the human stress-responsive $\mathrm{p} 38$ and JNK MAPK pathways. EMBO J. 17: $4744-4752$

24. Takekawa M, Adachi M, Nakahata A, Nakayama I, Itoh F, Tsukuda H, Taya Y and Imai K (2000) p53-inducible wip1 phosphatase mediates a negative feedback regulation of p38 MAPK-p53 signaling in response to UV radiation. EMBO J. 19: 6517-6526

25. Fiscella M, Zhang H, Fan S, Sakaguchi K, Shen S, Mercer WE, Vande Woude GF, O'Connor PM and Appella E (1997) Wip1, a novel human protein phosphatase that is induced in response to ionizing radiation in a p53dependent manner. Proc. Natl. Acad. Sci. USA 94: 6048-6053

26. Bulavin DV, Demidov ON, Saito S, Kauraniemi P, Phillips C, Amundson SA Ambrosino C, Sauter G, Nebreda AR, Anderson CW, Kallioniemi A, Fornace Jr
AJ and Appella E (2002) Amplification of PPM1D in human tumors abrogates p53 tumor-suppressor activity. Nat. Genet. 31: 210-215

27. Li J, Yang Y, Peng Y, Austin RJ, van Eyndhoven WG, Nguyen KC, Gabriele T, McCurrach ME, Marks JR, Hoey T, Lowe SW and Powers S (2002) Oncogenic properties of PPM1D located within a breast cancer amplification epicenter at 17q23. Nat. Genet. 31: 133-134

28. Saito-Ohara F, Imoto I, Inoue J, Hosoi H, Nakagawara A, Sugimoto T and Inazawa J (2003) PPM1D is a potential target for 17q gain in neuroblastoma. Cancer Res. 63: 1876-1883

29. Hirasawa A, Saito-Ohara F, Inoue J, Aoki D, Susumu N, Yokoyama T, Nozawa S, Inazawa J and Imoto I (2003) Association of 17q21-q24 gain in ovarian clear cell adenocarcinomas with poor prognosis and identification of PPM1D and APPBP2 as likely amplification targets. Clin. Cancer Res. 9: 1995-2004

30. Lu X, Bocangel D, Nannenga B, Yamaguchi H, Appella E and Donehower LA (2004) The p53-induced oncogenic phosphatase PPM1D interacts with uracil DNA glycosylase and suppresses base excision repair. Mol. Cell 15: 621-634

31. Ward IM, Wu X and Chen J (2001) Threonine 68 of Chk2 is phosphorylated at sites of DNA strand breaks. J. Biol. Chem. 276: 47755-47758

32. Xu X, Tsvetkov LM and Stern DF (2002) Chk2 activation and phosphorylationdependent oligomerization. Mol. Cell. Biol. 22: 4419-4432

33. Ahn JY, Li X, Davis HL and Canman CE (2002) Phosphorylation of threonine 68 promotes oligomerization and autophosphorylation of the Chk2 protein kinase via the forkhead-associated domain. J. Biol. Chem. 277: 19389-19395

34. Schwarz JK, Lovly CM and Piwnica-Worms H (2003) Regulation of the Chk2 protein kinase by oligomerization-mediated cis- and trans-phosphorylation Mol. Cancer Res. 1: 598-609

35. Wu X and Chen J (2003) Autophosphorylation of Chk2 at serine-516 is required for radiation-induced apoptosis. J. Biol. Chem. 278: 36163-36168

36. Choi J, Nannenga B, Demidov ON, Bulavin DV, Cooney A, Brayton C, Zhang Y, Mbawuike IN, Bradley A, Appella E and Donehower LA (2002) Mice deficient for the wild-type p53-induced phosphatase gene (Wip1) exhibit defects in reproductive organs, immune function, and cell cycle control. Mol. Cell. Biol. 22: 1094-1105

37. Bell DW, Varley JM, Szydlo TE, Kang DH, Wahrer DC, Shannon KE Lubratovich M, Verselis SJ, Isselbacher KJ, Fraumeni JF, Birch JM, Li FP, Garber JE and Haber DA (1999) Heterozygous germ line hCHK2 mutations in Li-Fraumeni syndrome. Science 286: 2528-2531

38. Bulavin DV, Phillips C, Nannenga B, Timofeev O, Donehower LA, Anderson CW, Appella E and Fornace Jr AJ (2004) Inactivation of the Wip1 phosphatase inhibits mammary tumorigenesis through p38 MAPK-mediated activation of the p16(Ink4a)-p19(Arf) pathway. Nat. Genet. 36: 343-350

39. Harrison M, Li J, Degenhardt Y, Hoey T and Powers S (2004) Wip1-deficient mice are resistant to common cancer genes. Trends Mol. Med. 10: 359-361

40. Lu X, Nannenga B and Donehower LA (2005) PPM1D dephosphorylates Chk1 and p53 and abrogates cell cycle checkpoints. Genes Dev. 19: 1162-1174

41. Yamaguchi H, Minopoli G, Demidov ON, Chatterjee DK, Anderson CW, Durell SR and Appella $E$ (2005) Substrate specificity of the human protein phosphatase 2Cdelta, Wip1. Biochemistry 44: 5285-5294

Supplementary Information accompanies the paper on Cell Death and Differentiation website (http://www.nature.com/cdd) 